\title{
Perfil epidemiológico da Covid-19 no Estado do Paraná
}

\author{
Epidemiological profile of Covid-19 in the State \\ of Paraná
}

Clara Inácio de Paiva ${ }^{1}$, Acácia Maria Lourenço Francisco Nasr ${ }^{2}$, Diego da Silva Magatão ${ }^{3}$ Rafael Gomes Ditterich, Raquel Rangel de Meireles Guimarães ${ }^{5}$, Rosana Aparecida Piler ${ }^{6}$, Carlos Alberto Gebrim Preto7, Nestor Werner Junior ${ }^{8}$, Maria Goretti David Lopes ${ }^{9}$, Vanessa Fredrich $^{10}$

1.ORCID: https://orcid.org/0000-0002-2692-6843. Acadêmica de Medicina na Pontifícia Universidade Católica do Paraná, campus Curitiba, Brasil. E-mail: clarappaiva@gmail.com.

2. ORCID: https://orcid.org/0000-0002-7663-6094. Doutoranda em políticas públicas pela UFPR Secretaria de Saúde do Estado do Paraná, Brasil. E-mail: acacianasr@gmail.com.

3. ORCID: http://orcid.org/0000-0002-1725-2576. Mestrando em Saúde Internacional e Medicina Tropical na London School of Hygiene and Tropical Medicine. Professor licenciado de Medicina na Faculdade Pequeno Príncipe, Curitiba, Paraná, Brasil. E-mail: diegomagatao@hotmail.com.

4. ORCID: https://orcid.org/0000-0001-8940-1836 Graduado em Odontologia pela Universidade Federal do Paraná, campus Curitiba. Secretaria de Saúde do Estado do Paraná, Brasil. E-mail: prof.rafaelgd@gmail.com

5. ORCID: https://orcid.org/0000-0003-1754-9238. Doutora em Demografia pela Universidade Federal de Minas Gerais (UFMG). Universidade Federal do Paraná (UFPR), Curitiba, Paraná, Brasil. E-mail: raquel.guimaraes@ufpr.br.

6. ORCID: http://orcid.org/0000-0001-9386-661X. Enfermeira chefe da Divisão de Vigilância das Doenças Transmissíveis da Secretaria de Saúde do Estado do Paraná, Curitiba, Brasil. E-mail: rosana.piler@sesa.pr.gov.br.

7. ORCID: https://orcid.org/0000-0002-7132-7372. Médico. Secretário de Estado da Saúde do Paraná, em Curitiba, Brasil. E-mail: betopreto@sesa.pr.gov.br.

8. ORCID: https://orcid.org/0000-0003-4257-1752 Graduado em Odontologia pela Pontifícia Universidade Católica do Paraná. Diretor Geral da Secretaria de Estado da Saúde do Paraná E-mail: nestor.jr@sesa.pr.gov.br.

9. ORCID: https://orcid.org/0000-0001-7473-6342. Enfermeira. Diretora de Atenção em Vigilância em Saúde da Secretaria de Estado da Saúde do Paraná, Brasil. E-mail: maria.lopes@sesa. pr.gov.br.

10. ORCID: https://orcid.org/0000-0002-2571-5358. Mestranda em Ensino das Ciências da Saúde. Médica da Vigilância Epidemiológica. E-mail: vanessa.fredrich@sesa.pr.gov.br.

CONTATO: Clara Inácio de Paiva | Endereço: Avenida Iguaçu, 3001. Telefone: (041) 99660-5364 | E-mail: clarappaiva@gmail.com 
RESUMO A pandemia de Covid-19 já causou mais de 990 mil óbitos pelo mundo. A doença, causada pelo coronavírus SARS-CoV-2, é um importante problema de saúde pública. Desde 12 de março até 28 de setembro de 2020, foram registrados 174.124 casos e 4.335 óbitos pela doença no Paraná. O estudo teve como objetivo traçar o perfil epidemiológico da Covid-19 no Paraná. Fez-se análise descritiva com dados do informe epidemiológico da Secretaria de Saúde do Estado. Até 28 de setembro de 2020, 1,5\% da população paranaense havia sido contaminada e $72,6 \%$ dos pacientes já estavam recuperados. A média de idade dos casos e óbitos foram, respectivamente, de 39,8 e 68,6 anos. Dos confirmados, 91.676 (53\%) eram do sexo feminino e dos óbitos, 2.599 (60\%) do masculino. Dos 906 (0,5\%) pacientes internados, 446 (49,2\%) estavam em UTI. A taxa de letalidade era de 2,5\%. É possível delinear o comportamento da doença no Estado.

DESCRITORES: Doença por Coronavírus. Perfil Epidemiológico. Pandemia.

ABSTRACT Covid-19 pandemic has already caused more than 990 thousand deaths worldwide. The coronavirus disease, due to SARS-CoV-2, is an important public health problem. From March 12 to September 28, 2020, Paraná has already registered 174.124 cases and 4.335 deaths. The aim of this study is to describe the epidemiological profile of Covid-19 in the state of Paraná. Data collection were informed by Health Secretary of Paraná. As of September $28,1,5 \%$ of Paraná population had been infected and $72,6 \%$ had recovered. The mean age of confirmed cases and deaths were 39,8 and 68,6 years old, respectively. Among confirmed cases, 91.676 (53\%) were female and among deaths, 2.599 (60\%) were male. 906 (0,5\%) were hospitalized, of which 446 $(49,2 \%)$ were in ICU bed. Mortality rate was 2,5\%. It is possible to determinate the disease's behavior in Paraná.

DESCRIPTORS: Coronavirus Infections. Health Profile. Pandemics.

\title{
INTRODUÇÃO
}

\author{
A \\ pandemia causada pelo novo coronavírus, SARS-CoV-2, decretada no \\ dia 11 de março de 2020, já afetou mais de 200 países, com mais de 33 \\ milhões de casos confirmados e 990 mil óbitos pelo mundo'. A Covid-19 teve \\ seu início em dezembro de 2019, em Wuhan, Hubei, na China. A doença pode
}


evoluir com Síndrome Respiratória Aguda Grave (SRAG), entre outras complicações, e causou um aumento importante de hospitalizações por pneumonia em vários países. A doença tornou-se um importante problema de saúde pública, de economia e política mundialmente².

O Brasil teve seu primeiro caso confirmado no dia 29 de fevereiro de $2020^{3}$. Até o dia 27 de setembro, o país apresentava quase 5 milhões de casos notificados e quase 150 mil óbitos confirmados pela doença'. De acordo com o Ministério da Saúde, duas situações eram consideradas como caso suspeito para Covid-19: paciente com Síndrome Gripal (SG) ou com SRAG4 ${ }^{4}$.

Considerava-se SG o indivíduo que apresentasse quadro respiratório agudo, com pelo menos dois dos seguintes sintomas: febre (aferida ou referida), tosse, dor de garganta, dor de cabeça, calafrios, coriza, distúrbios olfativos e/ou distúrbios gustativos. Para crianças, também era considerado obstrução nasal, na ausência de outro diagnóstico específico. E, para idosos, síncope, irritabilidade, confusão mental, excesso de sonolência e inapetência eram considerados critérios de agravamento 4 .

Já a SRAG era definida como SG, associada a dispneia/desconforto respiratório, pressão persistente no tórax, saturação de O2 menor que 95\% em ar ambiente ou coloração azulada dos lábios ou rosto. Para crianças, deveria também observar batimento de asa de nariz, cianose, tiragem intercostal, desidratação e inapetência ${ }^{4}$.

Até a última atualização desse trabalho, eram utilizados critérios clínico, clínico-epidemiológico, clínico-imagem e clínico-laboratorial para a confirmação de Covid-19. Isto é, indivíduos com SG ou SRAG associado a anosmia ou ageusia; a contato próximo ou domiciliar com indivíduo confirmado laboratorialmente com Covid-19 nos últimos 14 dias; à presença de imagem compatível com a doença; e a testes laboratoriais positivos para a doença, respectivamente ${ }^{4}$.

Os métodos diagnósticos laboratoriais utilizados para confirmar a doença em pacientes com SG ou SRAG eram através da biologia molecular, dos 
testes imunológicos ou da pesquisa de antígeno ${ }^{4}$. Para confirmação da doença, o método de reação em cadeia da polimerase em tempo real (RT-PCR) era considerado o padrão-ouro em indivíduos sintomáticos ${ }^{5}$ : detecta partículas do RNA viral em amostras do trato respiratório superior (swab de nasofaringe e de orofaringe) ou inferior (escarro, lavado broncoalveolar ou aspirado traqueal). Recomendava-se a realização do swab até o oitavo dia do início dos sintomas 6 .

Para melhor precisão diagnóstica, recomendava-se que os testes imunológicos fossem realizados a partir do oitavo dia dos sintomas ${ }^{6}$. Embora estivessem no critério clínico-laboratorial para a doença, era considerado melhor para auxiliar no mapeamento epidemiológico da Covid-19, pela detecção de anticorpos e pela resposta imune humoral secundária a infecção ${ }^{7}$. Ou seja, possuíam mais valor para vigilância da doença.

No Brasil, nessa época, deveriam ser notificados indivíduos com SG ou com SRAG hospitalizado; óbitos por SRAG, independente da hospitalização, que entrassem na definição de casos explicado acima e pacientes assintomáticos, com confirmação laboratorial por biologia molecular ou imunológico de infecção recente por Covid-194.

O Paraná, por sua vez, teve seu primeiro caso registrado no dia 28 de setembro de $2020^{1}$. Até esta data, o número de casos confirmados e de óbitos no estado eram de 174.124 e 4.335 , respectivamente 1 . O estado apresentou um aumento importante no número de casos de Covid-19, principalmente do mês de maio para junho, coincidindo com o período sazonal de outono e inverno, e o aumento das doenças respiratórias, seja por SG ou por SRAG causada por outros agentes etiológicos ${ }^{8}$. As características da população paranaense infectada pelo vírus, a dinâmica e a gravidade da doença, bem como a ocupação da doença no sistema de saúde do Estado, ainda não foram descritas em artigo.

A dimensão e a diversidade socioeconômica do território brasileiro tornam o cenário amplamente variado não somente entre as uniões federativas do país, como também dentro de um próprio Estado 9 . Por isso, este estudo visa 
analisar o perfil epidemiológico da doença focada no Paraná. Desse modo, ao entender a dinâmica da doença no Estado durante a pandemia, será possível avaliar a efetividade das medidas propostas e otimizar as estratégias de combate à Covid-19.

\section{MÉTODO}

Este estudo é uma análise descritiva, com base nos dados da Secretaria de Saúde do Estado do Paraná (SESA-PR), disponíveis no boletim diário da Vigilância Epidemiológica do dia 28 de setembro de 2020, data da última atualização deste trabalho. Os dados de casos confirmados de residentes no Paraná são consultados na planiIha de monitoramento diário de casos do Centro de Informações Estratégicas em Vigilância em Saúde (CIEVS)/Diretoria de Atenção e Vigilância (DAV)/SESA.

A análise descritiva foi realizada a partir do número de casos confirmados e óbitos, faixa etária, sexo, raça/cor, evolução dos casos confirmados, perfil dos pacientes internados, taxa de ocupação de leitos clínicos e de unidade de terapia intensiva (UTI), municípios de residência dos casos e óbitos e suas características.

Os métodos laboratoriais para diagnóstico do Covid-19 eram através da biologia molecular, dos testes imunológicos ou da pesquisa de antígeno. O primeiro realizado pelo método RT-PCR, para detecção de SARS-CoV-2. Os testes imunológicos deveriam ser reagentes para IgM, IgA e/ou IgG, pelos métodos: Ensaio imunoenzimático (Enzyme-Linked Immunosorbent Assay - ELISA); Imunocromatografia (teste rápido); Imunoensaio por Eletroquimioluminescência (ECLIA). Na pesquisa de antígeno, era utilizado o método de Imunocromatografia. Os testes com resultado positivo deveriam ser registrados no sistema Gerenciador de Ambiente Laboratorial (GAL)7.

Os testes aprovados e registrados pela Agência Nacional de Vigilância Sanitária (Anvisa) até o momento são: ONE STEP COVID-2019 TEST®, MEDTESTE CORONAVÍRUS (COVID-19) IgG/IgM®, COVID-19 IgG/IgM ECO®, COVID-19 IgG/IgM BIO®, SARS-CoV2 Antibody Test ${ }$, COVID-19 IgG/IgM RAPID COMBO ECO TEST®, COVID-19 iGg/iGm rapid test ${ }$. 
Os fatores de risco em casos confirmados hospitalizados por Covid-19 e os óbitos pela doença foram avaliados através do que estava constatado na ficha do Sistema de informação de Vigilância Epidemiológica da Gripe (Sivep-gripe). Não foram incluídas, nessa análise, comorbidades como hipertensão e neoplasia, uma vez que não estavam constadas nos campos do Sivep-gripe.

Os pacientes internados, em enfermaria e UTIs, eram contabilizados tanto do ambiente hospitalar público (SUS), quanto do particular. E os casos recuperados são monitorados pela Vigilância Epidemiológica da SESA-PR, a partir de informações encaminhadas às regionais de saúde pelos municípios.

A ocupação de leitos hospitalares exclusivos do SUS para pacientes suspeitos ou confirmados com Covid-19 por macrorregião era avaliada pela regulação de leitos da Diretoria de Gestão de Saúde (DGS)/SESA; Sistema Estadual de Regulação, Secretaria Municipal de Saúde (SMS) de Curitiba, de São José dos Pinhais, de Araucária e de Pato Branco.

O coeficiente de incidência e de mortalidade por Regional de Saúde (RS) são casos e óbitos confirmados por 100.000 habitantes e têm como comparativo a incidência estadual. Era dividido em três classificações: alerta, se a regional estivesse com o coeficiente abaixo da incidência estadual; atenção, se estivesse entre 50\% e a incidência estadual; e emergência, se 50\% acima da incidência estadual.

\section{RESULTADOS}

Até a última atualização desse trabalho, os casos e os óbitos acumulados pela Covid-19, respectivamente, eram de 33.034.598 e 996.342, no Mundo, 4.717 .991 e 141.406, no Brasil e 174.124 e 4.335, no Paraná. No dia anterior a essa data, haviam sido registrados mais 832 novos casos e mais 20 óbitos em decorrência da infecção causada pelo SARS-CoV-2 no Estado do Paraná. Nessa época, 398 munícipios paranaenses possuíam pelo menos um caso confirmado pela Covid-19, representando $99 \%$ do total de cidades. No Gráfico 1, há a evolução de casos confirmados e óbitos 
acumulados por data de divulgação semanal.

Gráfico 1. Casos novos e óbitos acumulados por data de divulgação semanal.

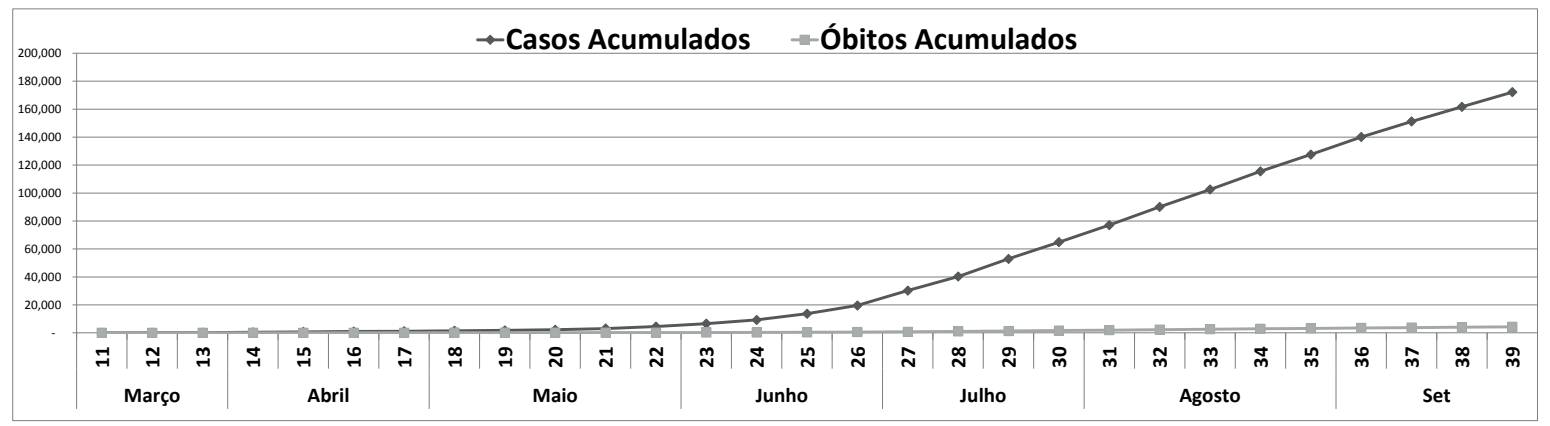

Fonte: Elaborado pelos autores (2020).

Dentre os 11.468.819 de habitantes do Paraná, foram confirmados 174.124 casos, o que representava 1,5\% da população paranaense. A média de idade foi de 39,8 anos e a faixa etária de maior prevalência foi entre 30-39 anos, em ambos os sexos. Foram registrados 23.721 casos nessa faixa etária, o que representa $13,6 \%$ dos confirmados. Do total de confirmados, houve discreto predomínio no sexo feminino ( $n=91.676$ [53\%]).

Já a média de idade dos óbitos pela doença foi maior e foi de 68,6 anos. A maioria dos óbitos ocorreu em pacientes do sexo masculino $(n=2.599$ [60\%]), entre 70 e 79 anos de idade. No Gráfico 2, há um resumo dos casos e óbitos por sexo e por faixa etária.

Gráfico 2. Casos e óbitos por sexo e faixa etária.
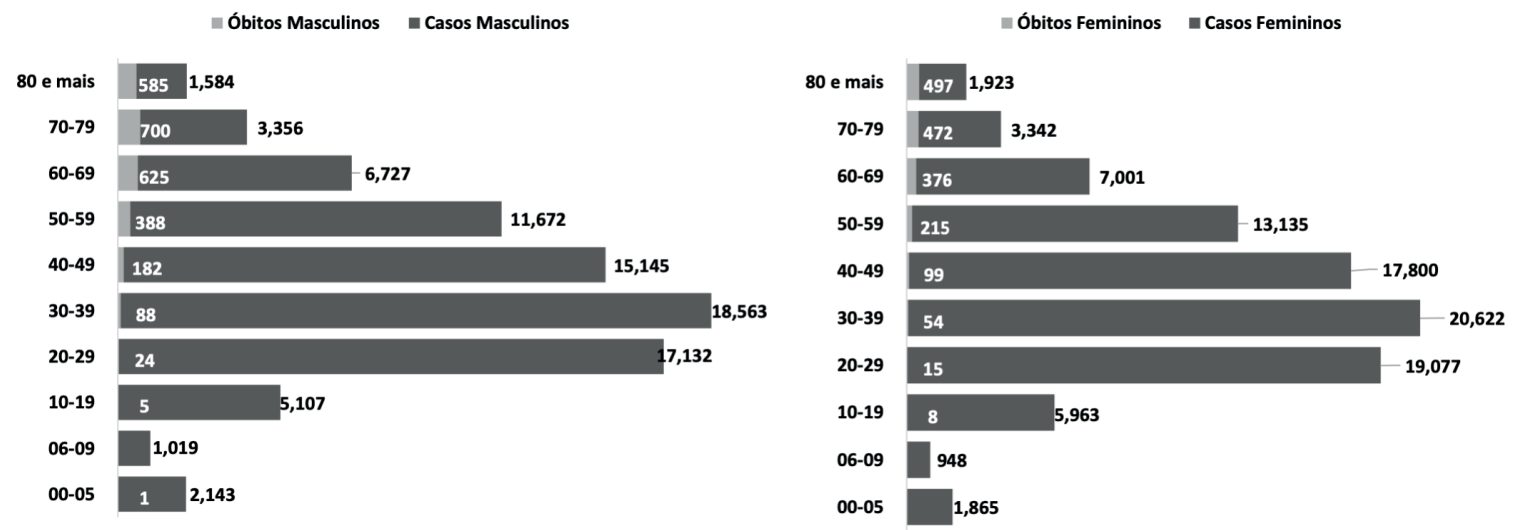

Fonte: Elaborado pelos autores (2020). 
Dos 174.124 casos confirmados, 126.337 (72,6\%) pacientes já estavam recuperados, 906 (0,5\%) encontravam-se internados - 460 (50,8\%) em leitos clínicos e 446 $(49,2 \%)$ em leitos de UTI - e 4.335 (2,5\%) haviam ido a óbito pela infecção do SARS-CoV-2.

Foram notificados um total de 46.197 casos de trabalhadores de saúde com suspeita de Covid-19, sendo que 7.704 tiveram resultado positivo, tanto pelo método PCR quanto pelo teste sorológico. Entre os grupos que tiveram a ocupação informada, o grupo de enfermagem apresentou o maior número de confirmados (3.301), seguido de médico (658), da área administrativa (383), de agente comunitário de Saúde (336) e de serviços (286).

Dentre pacientes hospitalizados por Covid-19, 9.616 apresentavam fator de risco associado, o que representa $66 \%$ da amostra. Os três fatores de risco mais prevalentes foram: idoso $(7.208$ [49,5\%]), presença de doença cardiovascular crônica $(5.006$ [34,37\%]) e Diabetes mellitus (3.348 [22,99]). Em seguida, obesidade (892 [6,13\%]), doença neurológica crônica (754 [5,18\%]), pneumopatias crônicas (719 [4,94\%]), doença renal crônica (642 [4,41\%]), asma (458 [3,14\%]), imunodeficiência (398 [2,73\%]), doença hepática (148 [1,02\%]). Crianças menores de 6 anos representavam menos do que $1 \%$ dos internamentos (105 [0,71\%]), e a população indígena menos do que $0,1 \%(11[0,08 \%]$.

Entre 3.961 óbitos, a maioria possuía algum fator de risco associado (3.256 [82\%]). Esse valor de óbitos é parcial, uma vez que se refere ao número informado pelos municípios e no Sistema de Informações sobre Mortalidade (SIM). Grande parte dos óbitos ocorreu em idosos (3.000 [75,38\%]). Em seguida, as seis comorbidades mais prevalentes foram doença cardiovascular crônica (46,73\%), Diabetes mellitus $(31,85 \%)$, doença neurológica crônica $(9,79 \%)$, doença renal crônica (8,39\%), pneumopatias crônicas (8,23\%) e obesidade $(6,66 \%)$.

O perfil dos casos confirmados hospitalizados segundo raça/cor foi de 9.625 (85\%) em brancos, seguida de 1.533 (14\%) da negra - inclui-se pardos e pretos -, 123 (1\%) da amarela e 11 (<1\%) da indígena. Já em relação aos óbitos, segundo essa 
divisão, foi de 2.599 (83\%) da cor branca, seguida de 480 (15\%) da negra, de 45 (2\%) da amarela e de $5(<1 \%)$ da indígena. Os óbitos segundo raça/cor ocorreram em 2.599 de 9.625 (27\%) brancos, em 480 de 1.533 (31,3\%) negros, em 5 de 11 (45,5\%) indígenas e em 45 de $123(36,5 \%)$ da amarela.

Até o dia 27 de setembro, o Estado possuía 2.677 leitos exclusivos para pacientes suspeitos ou confirmados com Covid-19, nas redes públicas e particulares. Eram 1.085 leitos de UTI adulto, 44 UTIs pediátricas e 1.489 de enfermaria, dos quais 59 pediátricos.

Dos pacientes internados, 906 pacientes eram confirmados com Covid-19, sendo que 758 encontravam-se em leitos da rede SUS (383 em UTI e 375 em leitos clínicos) e 148 em leitos da rede privada (63 em UTI e 85 em leitos clínicos). A maioria dos internamentos, porém, eram de casos suspeitos, com 999 pacientes ainda sem resultado dos exames: 944 encontravam-se internados na rede pública (420 na UTI e 524 na enfermaria) e 55 na rede privada (26 em leitos UTI e 29 em clínico).

A taxa de ocupação em todo o Paraná até essa data era de $73 \%$ em UTI adulto e $50 \%$ em enfermaria adulto; e $29 \%$ em UTI pediátrico e $24 \%$ em enfermaria pediátrica. A quantidade de leitos disponíveis e ocupados e a taxa de ocupação por macrorregião, nessa época, estão resumidas na Tabela 1.

Tabela 1. Leitos hospitalares SUS para pacientes suspeitos ou confirmados Covid-19, por macrorregião.

\begin{tabular}{|c|c|c|c|c|c|c|c|c|c|c|c|c|c|c|c|c|}
\hline & \multicolumn{8}{|c|}{ Adulto } & \multicolumn{8}{|c|}{ Pediátrico } \\
\hline & \multicolumn{4}{|c|}{ UTI } & \multicolumn{4}{|c|}{ Enfermaria } & \multicolumn{4}{|c|}{ UTI } & \multicolumn{4}{|c|}{ Enfermaria } \\
\hline & Exist. & Ocup. & Livre & $\begin{array}{l}\text { Tx de } \\
\text { ocup }\end{array}$ & Exist. & Ocup. & Livre & $\begin{array}{l}\text { Tx de } \\
\text { ocup. }\end{array}$ & Exist. & Ocup. & Livre & $\begin{array}{l}\text { Tx de } \\
\text { ocup. }\end{array}$ & Exist. & Ocup. & Livre & $\begin{array}{l}\text { Tx de } \\
\text { ocup. }\end{array}$ \\
\hline Leste & 575 & 465 & 110 & $81 \%$ & 768 & 374 & 394 & $49 \%$ & 16 & 12 & 4 & $75 \%$ & 22 & 12 & 10 & $55 \%$ \\
\hline Oeste & 156 & 91 & 65 & $58 \%$ & 184 & 97 & 87 & $53 \%$ & 2 & 1 & 1 & $50 \%$ & 3 & 0 & 3 & $0 \%$ \\
\hline Noroeste & 148 & 75 & 73 & $51 \%$ & 274 & 54 & 220 & $20 \%$ & 11 & 0 & 11 & $0 \%$ & 20 & 1 & 19 & $5 \%$ \\
\hline Norte & 206 & 104 & 102 & $50 \%$ & 263 & 99 & 164 & $38 \%$ & 15 & 2 & 13 & $13 \%$ & 14 & 0 & 14 & $0 \%$ \\
\hline Total & 1.085 & 735 & 350 & $68 \%$ & 1.489 & 624 & 865 & $42 \%$ & 44 & 15 & 29 & $34 \%$ & 59 & 13 & 46 & $22 \%$ \\
\hline
\end{tabular}

Fonte: Elaborado pelos autores (2020). 
Quanto à testagem para a presença de SARS-CoV-2, já haviam sido realizados 960.484 testes RT-PCR, registrados no GAL. 498.555 foram negativos e 4.989 ainda estavam em investigação. Haviam sido confirmados 156.788 testes pelos critérios RT-PCT, clínico epidemiológico ou teste rápido. A capacidade de processamento para exames com o método RT-PCR pelo Laboratório Central (LACEN) e Instituto de Biologia Molecular do Paraná (IBMP) era de 5.600 por dia. Em relação aos testes rápidos, o MS tinha entregado 427.980 "One Step Test" para a rede estadual, até a última atualização desse trabalho (27/09/2020).

A proporção de SG positivo para Covid-19 por testes realizados, durante o primeiro caso confirmado até a semana epidemiológica (SE) 37, variou entre $5-29 \%$. No entanto, os valores se mantiveram abaixo de $20 \%$ até a SE 20 , e acima de $20 \%$ desde então. O mesmo acontecendo em relação à proporção de SRAG positiva para Covid-19 por testes realizados. No entanto, nesse caso, as taxas se mantiveram mais altas, entre 22 e $52 \%$.

Ao comparar o coeficiente de incidência (casos por 100 mil habitantes) das regionais de saúde (RS) com a incidência estadual, a maioria delas encontravam-se abaixo do valor do estado. No entanto, oito de 22 RS estavam acima do valor do Estado (1.511). Uma delas classificada como emergência: a 9a RS Foz do Iguaçu. E sete delas classificadas como atenção.

Quanto ao coeficiente de mortalidade (óbitos por 100 mil habitantes), o Paraná apresentava um valor de 37,6. Todos as regionais de saúde do Estado do Paraná apresentaram coeficiente abaixo da incidência nacional. No entanto, seis delas encontravam-se acima do coeficiente de mortalidade do Estado. Uma delas classificada como emergência: a $2^{\text {a }}$ RS Metropolitana, com coeficiente de mortalidade de 58,7. O restante classificado como atenção.

Nos Gráficos 3 e 4 estão os valores de coeficientes de incidência e de mortalidade, respectivamente, por RS. 
Gráfico 3. Coeficiente de Incidência por Regional de Saúde.

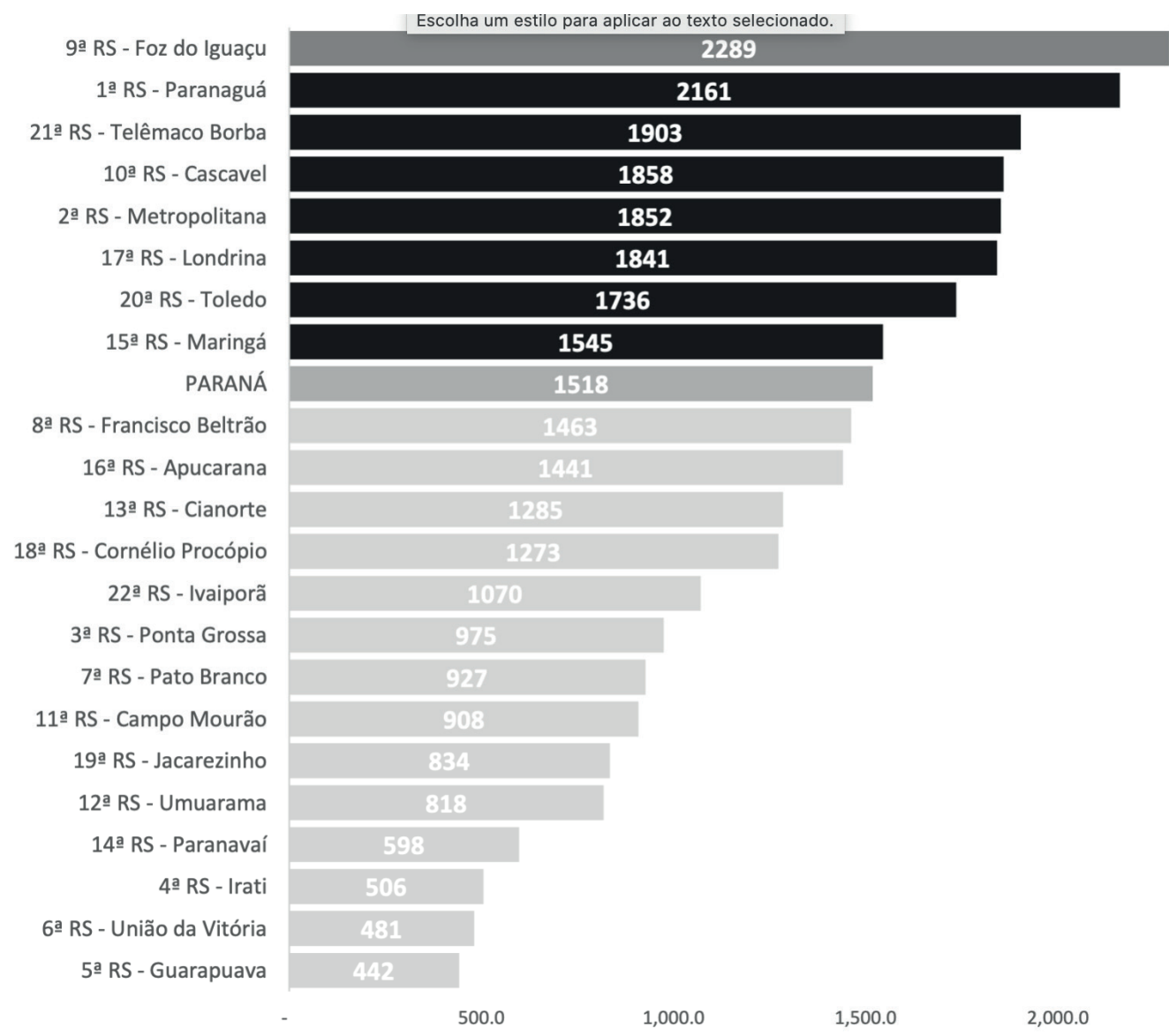

Fonte: Elaborado pelos autores (2020).

Em valores absolutos, a $2^{\text {a }}$ RS Metropolitana teve a maior quantidade de casos confirmados por Covid-19 ( $n=42.952)$, seguida da $17^{\mathrm{a}} \mathrm{RS}$ Londrina $(\mathrm{n}=7.917)$, da $10^{\mathrm{a}}$ RS Cascavel ( $n=7.308)$, da $15^{\text {a }}$ RS Maringá ( $\left.n=6.971\right)$ e da $9^{a}$ RS Foz do Iguaçu ( $\left.n=5.502\right)$. $\mathrm{A} 2^{\mathrm{a}}$ RS Metropolitana também teve o maior número de óbitos ( $\left.\mathrm{n}=1.384\right)$, seguida da $17^{\text {a }}$ RS Londrina ( $n=203$ ) e da $10^{\text {a }}$ RS Cascavel $(n=146)$.

Da SE 39 em relação à semana anterior, houve decréscimo de casos e óbitos em todo o Estado. Dos casos, houve decréscimo de 14,3\% no Paraná. Por macrorregião, os decréscimos foram de $14,1 \%$ no Leste, de $17,8 \%$ no Oeste, de $13,3 \%$ no Noroeste e de $12,1 \%$ no Norte. Na semana 38, havia um total de 217 óbitos registrados, ao final da semana 39, esse valor reduziu 13,4\%, totalizando 188 óbitos na semana. 
Gráfico 4. Coeficiente de Mortalidade por Regional de Saúde.
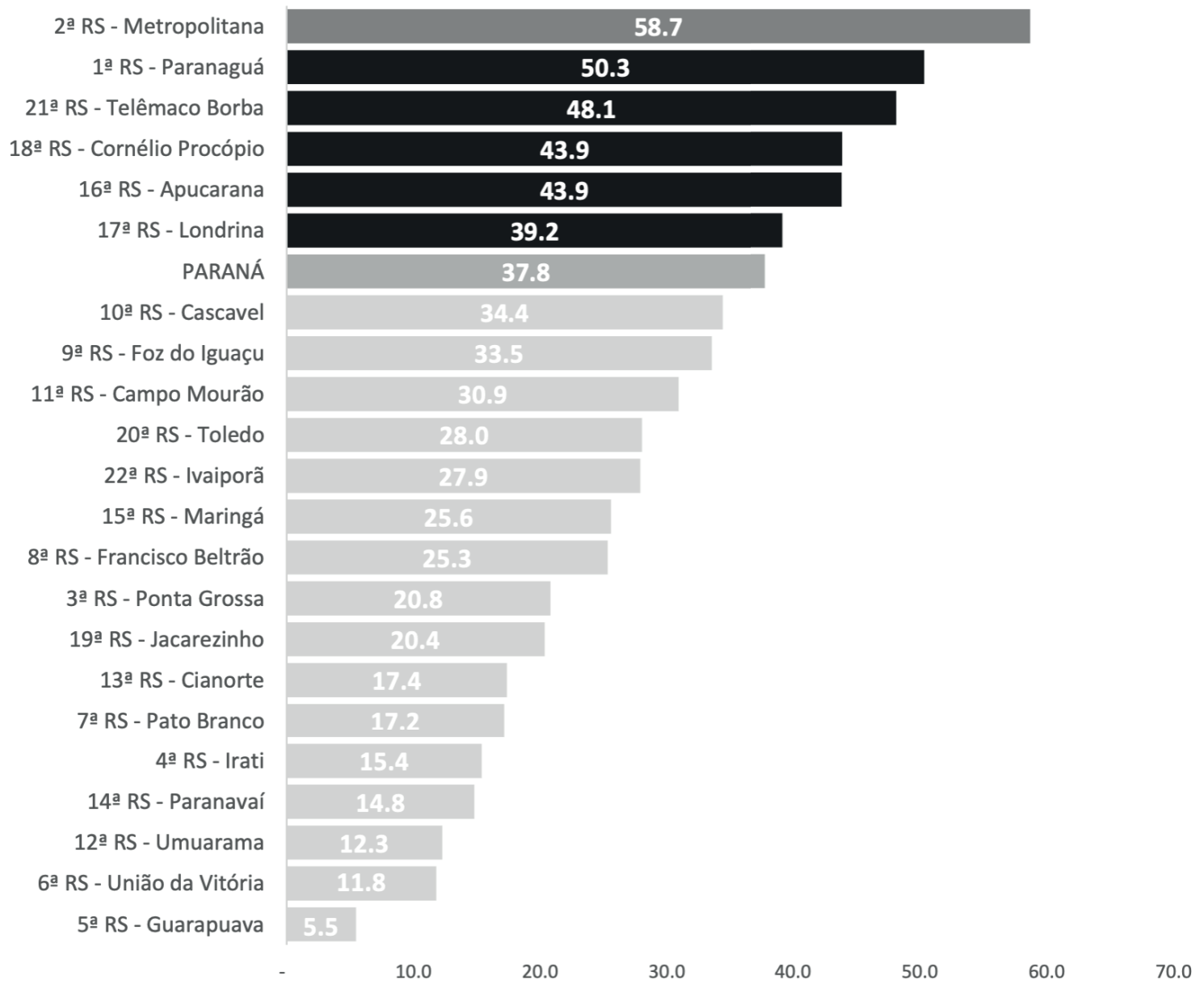

Fonte: Elaborado pelos autores (2020).

\section{DISCUSSÃO}

Até o dia 27 de setembro de 2020, a América Latina era o epicentro de Covid-19. O Brasil era o terceiro país com maior número de casos confirmados, ficando atrás apenas dos Estados Unidos da América (EUA) e da Índia ${ }^{10}$. Em relação aos óbitos, porém, o território brasileiro apresentava o segundo maior número registrado no mundo ${ }^{10}$.

No território brasileiro, o Paraná, por sua vez, era a Unidade Federativa (UF) com o $11^{\circ}$ maior número de casos confirmados e $10^{\circ}$ maior número de óbitos do país ${ }^{11}$. Desde o começo da pandemia até o dia 27/09/2020, praticamente 
todo o Estado tinha pelo menos um caso confirmado de Covid-19². Análise do Núcleo de Estudos em Economia Social e Demografia Econômica (NESDE) sugeria que a proximidade entre municípios, a migração pendular, e a facilidade de deslocamento foram fatores importantes na disseminação do SARS-CoV-2 para o interior do Estado ${ }^{12}$.

Embora as fronteiras entre os países vizinhos (Paraguai e Argentina) estivessem fechadas, as interações interestaduais se mantiveram abertas. As conexões nas divisas com São Paulo via BR-116 (Regis Bittencourt), com Santa Catarina via BR-191 e BR-153, entre outras conexões rodoviárias, também facilitavam o contato entre pessoas de diferentes localidades ${ }^{13}$.

O aumento de casos e óbitos acumulados ocorreu de maio para junho no Paraná, coincidindo não apenas com o período de outono e inverno ${ }^{8}$, mas também com o crescimento da prevalência de anticorpo para SARS-CoV-2 no Brasil, onde houve um aumento de cerca de 50\% entre as semanas dos dias 14-21 de maio a 4-7 de julho33. Segundo análise do NESDE, no mesmo período, o número de casos no Paraná dobrava a cada 12 dias, o que demonstra conexão do aumento no número de casos entre os estados brasileiros, sem barreiras de interações.

Até o dia 6 de julho, as taxas de crescimento eram aceleradas, sendo cerca de 1,06, o que significava um aumento de $6 \%$ de novos casos por dia. Em julho, houve aumento de $194 \%$ de novos casos em relação ao mês de junho, em agosto esse aumento foi de $5 \%$ e em setembro houve redução de $16 \%$ dos casos. Ainda que o mês de julho apresentasse o maior percentual de crescimento, o mês de agosto foi o que mais contribuiu com novos casos $(55.200)^{14}$.

Em relação aos confirmados, o Paraná apresentava uma grande quantidade de casos entre a população economicamente ativa de 15 a 59 anos, similar ao visto em um estudo com a população brasileira³. Quanto à média de idade do Estado, foi abaixo da registrada na população chinesa (40 anos vs. 47 anos) $)^{1,15}$. E houve prevalência no sexo feminino, diferente do registrado no estudo oriental 
citado (53\% vs. $41.9 \%)^{1,15}$. Além disso, a progressão da pandemia no Estado não seguiu conforme o padrão chinês, isto é, com 0,5\% da população infectada pelo SARS-CoV-2 ${ }^{15}$. A porcentagem no Paraná, nessa época, já era três vezes maior.

O baixo número de casos na população pediátrica pode ser atribuído por duas razões. Por conta da não detecção da doença, pois a maioria dos casos nessa faixa etária apresentam sintomas leves ou são assintomáticos². Também pelo fechamento precoce de escolas, que reduz a transmissão do vírus ${ }^{16}$. Aproximadamente de 2 a 5\% dos indivíduos confirmados com Covid-19 possuíam menos de 18 anos $^{2}$. Entretanto, esse valor é cerca de 10\% na população paranaense.

No Estado, a maioria dos pacientes que foram a óbito eram do sexo masculino, tinham idade avançada e possuíam alguma comorbidade, dados já associados com a gravidade da doença ${ }^{15}$. Em um estudo com pacientes críticos de Nova York, a maioria dos pacientes que evoluíram para óbito encontravam-se na faixa etária entre 70-79, assim como o registrado no Paraná17.

A taxa de letalidade, ou seja, o número de óbitos por casos confirmados, foi menor no Paraná do que o registrado no Brasil $(2,5 \% \text { vs. } 3,0 \%)^{9}$, porém, maior do que na China $(2,5 \% \text { vs. } 1,4 \%)^{10}$. No entanto, a letalidade não representa a realidade e pode ser bem diferente do registrado ${ }^{18}$. Isso porque os óbitos ocorrem muito depois do início da doença, além de que o denominador pode ser muito maior, uma vez que há subnotificação e que casos leves e assintomáticos nem sempre são testados ${ }^{18}$. O período de incubação do vírus é de cerca de 14 dias, do início dos sintomas à admissão em leitos de UTI é cerca de 10 dias e ao óbito pode variar de duas até oito semanas ${ }^{18}$.

Entre os profissionais de saúde no Paraná, o grupo de enfermagem, que é o que apresenta maior contato com os pacientes, foi o mais afetado e representou quase metade dos confirmados. No estudo que encontrou soroprevalência positiva significativamente maior nos trabalhadores de saúde, enfermeiros e técnicos de enfermagem representavam 4,03\% e 4,65\%, respectivamente ${ }^{19}$. Há 
limitação de comparação, uma vez que os dados do informe não são subcategorizados por tipo de profissional de enfermagem, nem por tipo de teste para confirmação.

Ainda há uma lacuna de informações quanto às infecções por SARS-CoV-2 nos profissionais de saúde. Há outras análises que sugerem taxa de infecção em trabalhadores de saúde como consequência da transmissão comunitária não intra-hospitalar ${ }^{20}$. Isso pode variar conforme as medidas comportamentais dentro e fora do ambiente de trabalho, o uso de equipamentos de proteção individual (EPIs) e contato com paciente confirmado ${ }^{20}$. Por isso, mais estudos são necessários para concluir se os profissionais de saúde do Estado do Paraná estão mais suscetíveis à infecção pelo SARS-CoV-2.

Dentre pacientes internados por Covid-19, 9.616 apresentavam algum fator de risco, o que representava $66 \%$ da amostra. Essa taxa é $16 \%$ menor, quando comparado com o estudo na cidade de Nova York ${ }^{17}$. No Paraná, quase metade da população internada era idosa e 1/3 apresentava doença cardiovascular crônica, fatores de risco independentemente associados à maior mortalidade intra-hospitalar, segundo esse estudo ${ }^{17}$.

As comorbidades mais prevalentes registradas no estudo nova iorquino foram Hipertensão (HAS) (63\%) e Diabetes Mellitus (DM) (36\%), enquanto no informe epidemiológico paranaense foram doença cardiovascular (DCV) crônica (34,37\%) e DM (22,99\%). Comorbidades que aumentam a gravidade da doença: DM, a segunda mais prevalente em ambas análises, assim como HAS, triplicam a chance de internamento em pacientes infectados com SARS-CoV-2 ${ }^{17,21}$.

Menos de $10 \%$ dos pacientes internados e que evoluíram para óbito apresentavam obesidade, dado em desacordo com o estudo supracitado, em que quase metade dos pacientes críticos eram obesos. Foi visto que pessoas com índice de massa corporal $\geq 30$ e $\geq 40$ apresentavam, respectivamente, 3 e 4,5 vezes mais risco de internação do que a população saudável21. No Paraná, esse resultado precisa ser analisado para entender como a obesidade interfere na gravidade da 
doença na população paranaense.

Estudos apontam que os grupos de minoria étnica e racial apresentam maior incidência de gravidade e de mortalidade na doença Covid-193,17,22,23. Nota-se que no Paraná, embora a maioria dos internamentos seja de pessoas da cor branca (85\%), mais negros do que brancos morrem no ambiente hospitalar (27 vs. 31\%). Dado encontrado em um estudo com a população brasileira, o qual relatou que o segundo fator de risco mais importante para a mortalidade intra-hospitalar, depois da idade, é ser pardo, e em menor proporção, ser preto 9 .

Vale ressaltar que esse dado não reflete a ligação direta entre doença e raça, mas sim a desigualdade socioeconômica existente. O acesso a saúde, a estabilidade econômica e a estrutura laboral da população de minoria étnica e racial contribuem para o pior prognóstico da doença nessa população ${ }^{22,23}$. Pela análise, foi visto que os brancos possuem mais acesso a leitos de UTI quando hospitalizados do que os negros ${ }^{23}$.

No Paraná, embora representasse a menor porcentagem de pacientes internados entre o próprio grupo, o indígena obteve a maior taxa de letalidade quando comparado com as outras raças, quase metade dos pacientes indígenas internados foram a óbito ${ }^{1}$. No Brasil, a população indígena apresentou uma prevalência cerca de quatro vezes maior do que na população branca $\left(6,3\right.$ vs. 1,4) ${ }^{3}$, diferente dos internamentos paranaenses ${ }^{1}$. Concluiu-se nesse estudo que os indígenas apresentam maior risco para Covid-19, provavelmente por suscetibilidade genética, como visto em outros surtos, e pelas condições socioeconômicas e de moradia precárias ${ }^{3}$.

O valor dos pacientes internados com necessidade de tratamento em UTIs no Paraná é maior do que a margem esperada por um estudo já citado (46\% vs. $17-$ $35 \%)^{2-3}$. A mortalidade hospitalar por Covid-19 é cerca de 15-20\% e pode chegar a 40\%, quando os pacientes são admitidos em UTIs². Uma pesquisa dos internamentos na Lombardia também revelou tempo elevado de permanência em leitos de UTI, necessidade prolongada de ventilação mecânica e alta mortalidade 
em pacientes críticos com Covid-19 ${ }^{15}$. Isso gera implicações no sistema de saúde, como a necessidade de aumentar a capacidade de leitos de UTI e a quantidade de suporte para ventilação mecânica ${ }^{17}$.

Em análise do contexto em geral, a taxa de ocupação de leitos exclusivos para casos confirmados e suspeitos de Covid-19 era de $68 \%$ de leitos de UTI e mais da metade de leitos de enfermaria estavam disponíveis para adultos, no Paraná. Segundo método utilizado pelos EUA, possuir, pelo menos, 15\% de leitos de UTI disponíveis é considerado critério positivo para iniciar uma fase de reabertura ${ }^{24}$. O Estado, portanto, estaria dentro desse critério. No entanto, quando visto por macrorregião, o leste do Paraná, região mais populosa do Estado, apresentava quase $90 \%$ de ocupação. Ou seja, de acordo com a classificação dos EUA, sem considerar os outros critérios, o leste do Paraná necessitaria de máximo distanciamento social ${ }^{1,24}$.

Nota-se também que a taxa de ocupação em leitos de UTI e de enfermaria era mais do que o dobro para pacientes adultos do que pediátricos no Paraná1. Quando avaliado o perfil de internamentos no Estado, crianças menores de 6 anos representavam menos de $1 \%$ dos internamentos, semelhante ao encontrado em um estudo espanhol, onde crianças abaixo de 5 anos apresentam metade da prevalência de anticorpos contra SARS-CoV-2 se comparadas com adultos ${ }^{3}$.

Em relação aos testes realizados para Covid-19, a porcentagem de testes positivos no Paraná era de aproximadamente $24 \%$. Essa porcentagem chegou a $54 \%$ nos pacientes com SRAG. Esses valores não se enquadram na recomendação da OMS: sugere-se que os testes positivos estejam entre 3-12\% da testagem total25. Apresentar dados acima desses valores significa que há muito mais casos do que o relatado. Esses valores revelam, portanto, que havia uma notável subnotificação no Estado do Paraná e a testagem não estava sendo suficiente para ajudar no controle da pandemia ${ }^{25}$. O aumento da positividade no Estado coincidiu com o aumento de casos e óbitos por Covid-19, o que possivelmente indica limitação financeira do país e do Estado em fornecer maior quantidade de testes, conforme demanda. 
Austrália, Coreia do Sul e Uruguai - países considerados com a doença bem controlada - têm um percentual abaixo de $1 \%{ }^{25}$. Além disso, sabe-se que ampliar a capacidade do diagnóstico por meio do RT-PCR, exame padrão-ouro, é de suma importância. Foi visto que ampliar a testagem, diagnosticar precocemente os doentes e isolar os casos suspeitos, confirmados e os contatos são medidas que auxiliam na contenção da doença ${ }^{16}$.

Quanto à testagem sorológica em massa, vale ressaltar que a estratégia pode ser importante para entender a extensão da doença e os fatores de risco associados ${ }^{26}$. No entanto, o resultado positivo na presença dos sintomas iniciais não deve ser considerado como diagnóstico definitivo da doença, nem descarta totalmente o risco de uma segunda infecção ${ }^{26}$.

No dia 27 de setembro, o coeficiente de incidência do Paraná estava acima do Brasil (1.518 vs. 1.344), porém o de mortalidade estava menor $(37,8 \text { vs. } 45,9)^{11}$. Destacavam-se, nesse período, as $9^{\text {a }}$ RS Foz do Iguaçu e a $2^{\text {a }}$ RS Metropolitana, as duas regionais classificadas como emergência, com os maiores valores de incidência e de mortalidade, respectivamente.

No começo da pandemia, em maio, a 14 ${ }^{\text {a }}$ RS Paranavaí apresentava os maiores coeficientes de incidência e de óbitos (1.221 e 54) do Paraná. Pouco tempo depois, outros municípios dessa mesma regional passaram a ter também um elevado coeficiente de incidência. Padrão seguido em outras regionais: onde o coeficiente de incidência era alto, havia disseminação do vírus para os lugares vizinhos com baixa incidência ${ }^{12}$.

Nesse caso, o elevado coeficiente na regional foi explicado pelo setor industrial, que contava com mão de obra oriunda de diversos municípios - representa $14,1 \%$ do emprego formal local - e que não cessou suas atividades por causa da pandemia. As empresas de grande porte foram consideradas, portanto, possíveis focos de contágio e disseminação do vírus tanto para as cidades vizinhas, quanto para o Estado de São Paulo ${ }^{12}$.

Até a última atualização desse trabalho, porém, os valores da $14^{\mathrm{a}} \mathrm{RS}$, regional 
de maior preocupação no início da pandemia no Estado, tenderam à estabilização entre as semanas 16 e 26, segundo análise do NESDE, apresentando um percentual bem menor do que a média do Estado ${ }^{27}$. Da mesma forma pode acontecer com as outras regionais de saúde que estão com níveis elevados de incidência.

A $2^{\text {a }}$ RS Metropolitana, onde se encontra a capital do Estado, Curitiba, apresentava o maior coeficiente de mortalidade, acima do valor do Estado e do Brasil (58.4 vs. 37.6 vs. 45.9)1,11. No entanto, ao longo da pandemia, diferentes regionais ocuparam esse patamar. Isso não só porque a doença avança em diferentes fases entre as regionais, mas também porque as taxas de mortalidade podem variar de acordo com a quantidade de testes realizados, identificação de casos, critérios e condições de internação².

Era esperado também que a $2^{\text {a }}$ RS Metropolitana, a $17^{\text {a }}$ RS Londrina, a $15^{\text {a }}$ RS Maringá, a $10^{\text {a }}$ RS Cascavel e a $9^{a}$ RS Foz do Iguaçu estivessem entre as regionais com o maior número absoluto de casos, pois estão entre as mais populosas do Estado. A $3^{\text {a }}$ RS Ponta Grossa, porém, foge do esperado, uma vez que é a quarta RS mais populosa do Estado e apresenta menos casos (cerca de 6 mil casos) ${ }^{1}$. Quanto aos óbitos, as três regionais com o maior valor absoluto são as três mais populosas do Estado. Ainda assim, merece atenção, pois a grande conexão com centros vizinhos e zonas rurais ${ }^{25-26}$ fazem das grandes cidades potenciais focos de disseminação do vírus ${ }^{28}$.

No dia 27 de setembro de 2020, o Paraná apresentava um valor de R de 0,97 $(0,89-1,03)^{28}$. O valor de R ou número efetivo de reprodução da infecção (Rt) é um número epidemiológico que representa a média de pessoas que serão infectadas pelo SARS-CoV-2, a partir de uma pessoa com a doença. Considera-se que a epidemia está controlada quando Rt está abaixo de $1^{28}$. Valores acima de 1 revelam que o surto ainda não está controlado e que o número de casos tende a aumentar ${ }^{28}$. Consequentemente, a pressão no sistema de saúde também pode aumentar ${ }^{16}$. 
As intervenções não farmacológicas, como fechamento de escolas, bares e restaurantes, testagem de pessoas sintomáticas e distanciamento social têm sido ferramentas efetivas para a redução desse valor ${ }^{23}$, isto é, para a redução da transmissão da doença. O Rt demora de 2 a 3 semanas para se alterar após as mudanças comportamentais ${ }^{16}$.

Uma das estratégias que auxilia nessa redução é o isolamento social, em que o Paraná, no dia 28 de setembro, apresentava um índice de $48,8 \%{ }^{1}$. Ou seja, quase metade da população estava contribuindo para o controle da disseminação do vírus. O valor de Rt, associado ao índice de isolamento social, pode ser uma das formas de auxílio para as condutas e estratégias adotadas no combate ao Covid-19, tanto no Estado como um todo, quanto nas Regionais de Saúde e municípios do Paraná.

Outro método que auxiliaria nas estratégias do Paraná seria o dos EUA. O país adotou uma nova regra para avaliar qual fase de reabertura os estados estão: a fase 1, de máximo distanciamento social; a fase 2, o início da reabertura; a fase 3, a recuperação da economia; e 4, o novo normal. Cinco critérios são levados em consideração para essa classificação: incidência, testagem, monitorização de doentes e contactantes, leitos de UTI disponíveis e proteção para população de risco ${ }^{24}$.

Diante da ausência de vacina e de medicação antiviral específica, deve-se reforçar constantemente que as medidas comportamentais ainda são as principais ferramentas de combate ao novo coronavírus ${ }^{2,21}$. O uso de máscara, etiqueta respiratória, distanciamento social, detecção precoce com isolamento de casos e quarentena de contactantes continuam sendo necessários para controlar a transmissão do SARS-CoV-2 e atenuar os riscos sociais, econômicos e epidemiológicos gerados pela doença ${ }^{2,16,21}$.

Conclui-se que o Estado do Paraná seguiu alguns padrões previstos quando comparado com o Brasil e com outros lugares do mundo. No entanto, há particularidades e informações que ainda devem ser analisadas a fundo. 


\section{CONCLUSÃO}

Nosso estudo apresenta a importância de atualizar as estatísticas vitais para analisar o perfil epidemiológico, e demonstrar o cenário da Covid-19 no Paraná, assim como direcionar as ações dos gestores da saúde. $O$ trabalho apresenta algumas limitações, como a constante mudança de informações sobre a Covid-19, a exemplo da definição de casos confirmados pela doença, que foi mudada ao longo da pandemia e da progressão do conhecimento sobre a doença.

Além disso, a adesão da população em relação às medidas comportamentais e à reabertura do comércio fez com que houvesse importantes mudanças no cenário do Estado do Paraná, a princípio considerado exemplo no controle da disseminação do SARS-CoV-2. A taxa de letalidade também é uma limitação por não condizer com a realidade ${ }^{18}$, como já explicado ao longo do artigo.

No questionário do SIVEP-gripe para registro de pacientes internados com Covid-19 não havia informações sobre hipertensão e neoplasia, comorbidades importantes no comparativo de prevalência em pacientes mais graves, principalmente HAS, doença mais comumente encontrada ${ }^{17,29}$.

Por fim, a última limitação é em relação aos testes, cuja acurácia varia de acordo com método escolhido e com o dia de realização do teste a partir do início dos sintomas. A sorologia com IgM positivo tende a falso positivo. O IgG pode resultar falso positivo quando o paciente apresenta outras infecções virais, ou falso negativo, uma vez que o tempo da resposta imunológica varia em cada indivíduo. Os testes rápidos, portanto, quando negativos, não excluem a infecção pelo SARS-CoV-2, e, quando positivos, não confirmam a doença ${ }^{26}$.

Ademais, o trabalho da SESA-PR ao compartilhar informações com transparência e qualidade dos dados informados no boletim epidemiológico diário permite delinear a epidemia no Estado, desenvolver pesquisas acadêmicas que ajudam no progresso da ciência, orientar a população e propor medidas a fim de combater o Covid-19 no Estado do Paraná. 


\section{REFERÊNCIAS}

1. Secretaria de Saúde do Estado do Paraná (BR Informe epidemiológico Coronavírus (COVID-19) [Internet]. Curitiba: SESA; 2020. [citado em 2020 Out 5]. Disponível em: https://www.saude.pr.gov.br/sites/default/arquivos_restritos/files/ documento/2020-09/informe_epidemiologico_28_09_2020_.pdf.

2. Wiersinga WJ, Rhodes A, Cheng AC, Peacock SJ, Prescott HC. Pathophysiology, Transmission, Diagnosis, and Treatment of Coronavirus Disease 2019 (COVID-19): A Review [Internet]. [lugar desconhecido]: Jama; 2020. 1-13. Disponível em: https:// doi:10.1001/jama.2020.12839.

3. Hallal PC, Hartwig FP, Horta BL, Silveira MF, Struchiner CJ, Vidaletti LP, et al. SARS-CoV-2 antibody prevalence in Brazil: results from two successive nationwide serological household surveys [Internet]. Londres: Lancet Glob Heal; 2020. 0(0):1-9. Disponível em: https://doi:10.1016/S2214-109X(20)30387-9.

4. Ministério da Saúde. Definição de Caso e Notificação [Internet]. Brasil: Ministério da Saúde; 2020 [citado em 2020 Out 5]. Disponível em: https://coronavirus.saude.gov.br/definicao-de-caso-e-notificacao.

5. Sethuraman N, Jeremiah SS, Ryo A. Interpreting Diagnostic Tests for SARS-CoV-2 [Internet]. [lugar desconhecido]: JAMA - J Am Med Assoc.; 2020. Disponível em: https://doi:10.1001/jama.2020.8259.

6. Ministério da Saúde. Sobre a doença [internet]. Brasil: Ministério da Saúde; 2020. [acesso 2020 out 5]. Disponível em: https://coronavirus.saude.gov.br/sobre-a-doenca\#interna.

7. AB Fabiabo, MHR Letícia, GV Luciana, GX Sandra OS. Estratégias Laboratoriais Para Identificação Da Infecção Pelo Novo Coronavírus [Internet]. Belo Horizonte: Faculdade de Medicina UFMG; 2020. [citado em 2020 Jun 30]. Disponível em: https:// www.medicina.ufmg.br/coronavirus/wp-content/uploads/sites/91/2020/04/Estratégias-laboratoriais-para-identificação-dainfecção-pelo-novo-coronavírus.pdf.

8. Secretária de Saúde do Estado do Paraná. Informe Epidemiológico No 11 Vírus Respiratórios - Monitoramento até a Semana Epidemiológica 25 de 2020 [Internet]. Curitiba: SESA; 2020. [citado em 2020 Jun 23]. Disponível em: https://www. saude.pr.gov.br/sites/default/arquivos_restritos/files/documento/2020-06/influenza_24062020.pdf.

9. Baqui P, Bica I, Marra V, Ercole A, van der Schaar M. Ethnic and regional variations in hospital mortality from COVID-19 in Brazil: a cross-sectional observational study. Londres: Lancet Glob Heal; 2020. 0(0). Disponível em: https://doi:10.1016/ S2214-109X(20)30285-0.

10. WHO Coronavirus Disease (COVID-19) Dashboard [Internet]. Published September 28, 2020. [citado em 2020 Out 5]. Disponível em: https://covid19.who.int/.

11. PAINEL CONASS | COVID-19 [Internet]. 2020. [citado em 2020 Out 5]. Disponível em: https://www.conass.org.br/ painelconasscovid19/.

12. Ciminelli R, José Maranho E, Garcia J, Welters A. A covid-19 no estado do Paraná: canais de transmissão. [Nota técnica] Nesde/UFPR 02/20. Curitiba: UFPR e SESA; 2020. Disponível em: https://doi:10.17605/OSF.io/YTU3C.

13. Garcia J, Rolim C. Correlação espacial da covid-19 em municípios do estado do Paraná: Análise Ampliada. [Nota técnica] Nesde/UFPR 05/2020. Curitiba: UFPR e SESA; 2020. Disponível em: https://doi:10.17605/OSF.IO/YTU3C.

14. Paganotto, LA. Covid-19 no estado do Paraná: setembro de 2020. [Nota Técnica]. Nesde/UFPR 36/2020. Curitiba: UFPR e SESA; 2020. Disponível em: https://doi:10.17605/OSF.IO/YUT3C.

15. Guan W, Ni Z, Hu Y, Liang W, Ou C, He J, et al. Clinical characteristics of coronavirus disease 2019 in China. N Engl J Med; 2020. 382(18):1708-1720. Disponivel em: https://doi:10.1056/NEJMoa2002032.

16. Cowling BJ, Ali ST, Ng TWY, Tsang TK, Li JCM, Fong MW, et al. Impact assessment of non-pharmaceutical interventions against coronavirus disease 2019 and influenza in Hong Kong: an observational study. Londres: Lancet Public Heal; 2020. 2667(20). Disponível em: https://doi:10.1016/S2468-2667(20)30090-6.

17. Cummings MJ, Baldwin MR, Abrams D, Jacobson SD, Meyer BJ, Balough EM, et al. Epidemiology, clinical course, and outcomes of critically ill adults with COVID-19 in New York City: a prospective cohort study. medRxiv; 2020. Disponível em: https://doi:10.1101/2020.04.15.20067157.

18. Baud D, Qi X, Nielsen-Saines K, Musso D, Pomar L, Favre G. Real estimates of mortality following COVID-19 infection. Lancet Infect Dis.; 2020. 20(7):773. Disponível em: https://doi:10.1016/S1473-3099(20)30195-X.

19. Iversen K, Bundgaard H, Hasselbalch RB, Kristensen JH, Nielsen PB, Pries-Heje M, et al. Risk of COVID-19 in health-care workers in Denmark: an observational cohort study. Lancet Infect Dis.; 2020. 0(0). Disponível em: https://doi:10.1016/S14733099(20)30589-2. 
20. Pallett SJC, Rayment M, Patel A, Fitzgerald-Smith SAM, Denny SJ, Charani E, et al. Point-of-care serological assays for delayed SARS-CoV-2 case identification among health-care workers in the UK: a prospective multicentre cohort study. Lancet Respir Med.; 2020. 2600(20):1-10. Disponivel em: https://doi:10.1016/S2213-2600(20)30315-5.

21. Centers for Disease Control (US). COVID-19 Associated Hospitalization Related to Underlying Medical Conditions [Internet]. [local desconhecido: Centers for Disease Control and Prevention; 2020. [citado em 2020 Out 05]. Disponível em: https://www.cdc.gov/coronavirus/2019-ncov/covid-data/investigations-discovery/hospitalization-underlying-medicalconditions.html.

22. Killerby ME, Link-Gelles R, Haight SC, Schrodt CA, England L, Gomes DJ, et al. Characteristics Associated with Hospitalization Among Patients with COVID-19 - Metropolitan Atlanta, Georgia, March-April 2020. MMWR Morb Mortal Wkly Rep.; 2020. 69(25):790-794. Disponível em: https://doi:10.15585/mmwr.mm6925e1.

23. Baqui P, Bica I, Marra V, Ercole A, van der Schaar M. Ethnic and regional variations in hospital mortality from COVID-19 in Brazil: a cross-sectional observational study. Lancet Glob Heal.; 2020. 8(8):e1018-e1026. Disponível em: https://doi:10.1016/ S2214-109X(20)30285-0.

24. A Frontline Guide for Local Decision-Makers [Internet]. [local desconhecido]: Covid-Local; 2020. [citado em 2020 Ago 16]. Disponível em: www.covid-local.org.

25. Coronavirus (COVID-19) Testing - Statistics and Research. [Internet]. [lugar desconhecido]: Our World in Data; 2020 [citado em 2020 Jun 29]. Disponível em: https://ourworldindata.org/coronavirus-testing\#the-positive-rate-are-countriestesting-enough-to-monitor-their-outbreak.

26. Kadkhoda K. COVID-19 serologic testing: FAQs and caveats. Cleve Clin J Med. 2020. 87(6):329-333. Disponível em: https:// doi:10.3949/ccjm.87a.20054

27. Paganotto, LA. Evolução dos casos de covid-19 no Paraná por regional de saúde entre as semanas epidemiológicas 16 e 26. [Nota técnica] Nesde/UFPR 16/2020. Curitiba: UFPR e SESA; 2020. Disponível em: https://doi:10.17605/OSF.IO/YTU3C.

28. COVID-19 | Loft Data Science [Internet]. [citado em 2020 Out 05]. Disponível em: https://loft.science/.

29. Grasselli G, Greco M, Zanella A, Antonelli M, Cabrini L, Castelli A, et al. Risk Factors Associated With Mortality Among Patients With COVID-19 in Intensive Care Units in Lombardy, Italy. JAMA Intern Med; 2020 July. Disponível em: https:// doi:10.1001/jamainternmed.2020.3539.

\section{RECEBIDO:30/07/2020}

ACEITO: 07/10/2020 